\title{
RANCANG BANGUN APLIKASI PENGELOLAAN DATA PENJUALAN SEMBAKO BERBASIS DEKSTOP UNTUK UD. KERTA MANDALA SUMBAWA BESAR
}

\author{
Shinta Esabella ${ }^{1 *}$, Wayan Satru' ${ }^{2}$ Miftahul $\mathrm{Haq}^{3}$ \\ 1,2,3 Teknik Informatika, Universitas Teknologi Sumbawa \\ email: shinta.esabella@uts.ac.id*
}

\begin{abstract}
Abstrak: UD. Kerta Mandala Sumbawa Besar merupakan sebuah usaha dagang kecil yang bekerja di sektor distribusi sembako. Tingginya pembelian dan penjualan sembako menjadikan perusahaan ini menerima banyak transaksi dan pengiriman ke berbagai konsumen. Proses pengimputan manual menjadi salah satu hambatan yang sering dihadapi dalam pengelolaan data transaksi di CV. Mandala Bisnis Solusindo. Seperti data pelanggan, data produk yang dijual, serta data transaksi penjualan dan pembelian. Demi profesionalitas kinerja, setiap perusahaan atau jasa memerlukan pengelolaan data yang terstruktur dan efisien. Penelitian ini menghasilkan sebuah aplikasi berbasis desktop yang dapat mempermudah perusahaan dalam pengelolaan data transaksi yang efisien. Aplikasi ini dibuat menggunakan bahasa pemrograman Delphi 7 dan Microsoft Access sebagai database. Metode pengumpulan data yang digunakan berupa observasi, wawancara dan studi pustaka.
\end{abstract}

Kata Kunci : Aplikasi, Basis desktop, Penjualan

Abstract: UD. Kerta Mandala Sumbawa Besar is a small trading business that works in the basic food distribution sector. The high number of purchases and sales of groceries has made this company accept many transactions and deliveries to various consumers. The manual entry process is one of the obstacles that is often faced in managing transaction data in CV. Mandala Bisnis Solusindo. Such as customer data, data on products sold, and sales and purchase transaction data. For the sake of professional performance, every company or service requires structured and efficient data management. This study produces a desktop-based application that can facilitate companies in managing transaction data efficiently. This application was created using the Delphi 7 programming language and Microsoft Access as a database. Data collection methods used were observation, interviews and literature study.

Keywords : Applications, Desktop-based, Sales

\section{PENDAHULUAN}

Persaingan bisnis secara tidak langsung menuntut perusahaan dan jasa mengadopsi teknologi informasi sebagai penunjang kemajuan bisnis. Berperan sebagai alat atau sarana pendukung, teknologi informasi mengambil peran yang sangat penting untuk kelangsungan hidup jangka panjang sebuah perusahaan dan jasa serta meningkatkan profesionalitas di tengah persaingan bisnis. Sejalan dengan itu Widajanti, mengatakan globalisasi yang saat ini terjadi dapat mendorong perkembangan pasar dan bisnis bergerak sangat kompetitif serta mengakibatkan persaingan bisnis yang semakin kompleks [1].

UD. Kerta Mandala Sumbawa Besar merupakan sebuah usaha dagang kecil yang bekerja di sektor distribusi sembako. Pada penelitian ini, penulis mendapatkan kesempatan merancang dan membangun Aplikasi Pengelolaan Data Pembelian dan Penjualan Sembako Berbasis Dekstop untuk UD. Kerta Mandala Sumbawa Besar. Yang merupakan unit usaha bawahan CV. Mandala Bisnis Solusindo. Pembangunan Aplikasi dibuat menggunakan Delphi.7 dan Pembangunan database menggunakan DBMS (Database Management System) Microsoft Access.

Merancang dan membangun Aplikasi Pengelolaan Data Penjualan Sembako Berbasis Dekstop untuk UD. Kerta Mandala Sumbawa Besar, penulis membuat rancangan aplikasi dan database yang meliputi tabel User Login, tabel Menu Utama, tabel Produk, tabel Pelanggan, tabel Transaksi Penjualan, tabel Laporan Penjualan, dan tabel Pengguna Aplikasi.

Diharapkan hasil penelitian ini dapat menghasilkan aplikasi dan database yang dapat dikelola melalui Aplikasi Pengelolaan data Penjualan Sembako di UD. Kerta Mandala Sumbawa Besar, yang mudah digunakan dan membantu meminimalisir duplikasi data.

\section{TINJAUAN PUSTAKA Delphi}

Sejarah Munculnya Delphi dimulai dengan ide brilian Prof. Niclaus Wirth yang mengemukakan paparan tentang struktur data dan algoritma (Algorthm and Data Structure). Prof. Niclaus Wirth menerjemahkan paparan ini yang kemudian dikristalisasi ke dalam bahasa yang popular yang digunakan pertama kalinya sebagai bahasa yang berorientasi pada hal-hal yang Science dan Ilmiah yaitu Pascal. Pascal sendiri kemudian distandarisasikan kedalam ANSI PASCAL (Pascal Umum) oleh badan standarisasi Amerika Serikat (ANSI). Kemudian 20 november 1983, Borland melakukan riset untuk menerjemahkan ide dari kristalisasi ANSI Pascal (Pacal yang distandarisasi) yang kemudian memerlukan compiler pascal 
kedalam pengembangan perangkat lunaknya yaitu Turbo Pascal 1.0. Turbo Pascal 1. berjalan pada sistem operasi PC/MS DOS dengan keterbatasan memory yang saat itu bisa berjalan pada ukuran 1 Mbyte saja. Dari penemuan Turbo Pascal inilah akhirnya Delphi diciptakan.

Bahasa Delphi atau lebih dikenal pula sebagai object pascal (Pascal dengan ekstensi pemrograman berorientasi objek (PBO/OOP) pada mulanya ditunjukkan hanya untuk Microsoft Windows, namun saat ini telah mampu digunakan untuk mengembangkan aplikasi Linux dan Microsoft.NET framework. Khusus untuk pemrograman database, Borland Delphi menyedika fasilitas obyek yang kuat dan lengkap yang memudahkan programmer membuat program untuk aplikasi database. Format database yang memiliki Delphi adalah format database paradox, dBase, MS Access, ODBC, SyBASE, Oracle dan lain-lain. Delphi adalah compiler atau penterjemah bahasa Delphi (awalnya dari pascal) yang merupakan bahasa tingkat tinggi sekelas dengan Basic dan $C$. Bahasa pemrograman di Delphi disebut bahasa prosedural artinya bahasa atau sintaknya mengikuti urutan tertentu atau prosedur. Ada jenis pemrograman non-prosedural seperti pemrograman untuk kecerdasan buatan seperti bahasa Prolog. Delphi termasuk keluarga visual sekelas visual basic, visual $\mathrm{C}$, artinya perintahperintah untuk membuat objek dapat dilakukan secara visual. Pemrograman tinggal memilih objek apa yang ingin dimasukkan kedalam Form/Window, lalu tingkah laku objek tersebut saat menerima event/aksi tinggal dibuat programnya. Delphi merupakan bahasa berorientasi objek, artinya nama objek, property dan methode atau procedure dikemas menjadi satu kemasan (encapsulate).

\section{Microsoft Acces}

Microsoft Office Access adalah sebuah program aplikasi untuk membuat basis data komputer yang relasional yang ditujukan khusunya untuk basis data kalangan rumahan dan perusahaan kecil, hingga perusahaan menengah. Aplikasi ini merupakan anggota dari beberapsa aplikasi Microsoft Office, selain tentunya Microsoft Word, Microsoft Excel, dan Microsoft PowerPoint. Aplikasi ini menggunakan mesin basis data Microsoft Jet Database Engine, dan juga menggunakan tampilan grafis yang intuitif sehingga memudahkan pengguna. Versi terakhir adalah Microsoft Office Access 2007 yang termasuk ke dalam Microsoft Office System 2007.

Microsoft Access dapat menggunakan data yang disimpan di dalam format Microsoft Access, Microsoft Jet Database Engine, Microsoft SQL Server, Oracle Database, atau semua kontainer basis data yang mendukung standar ODBC.

\section{METODE}

Metode pengembangan yang digunakan untuk pengembangan perangkat lunak adalah model atau paradigma klasik yang sering disebut waterfall. Model ini sangat terstruktur dan bersifat. Metode ini memerlukan pendekatan yang sistematis dan sekuensial didalam system perangkat lunaknya. Pengembangan dimulai dari tingkat analisis, perancangan, implementasi dan pengujian. Dengan demikian terdapat aktivitas-aktivitas sebagai berikut:

a. Analisis

Pada tahap ini dilakukan pengumpulan kebutuhan-kebutuhan suatu system database yang harus dikenal terlebih dahulu bagianbagian dari aplikasi yang akan berintegrasi sistem database. Hasil akhir dari tahap ini adalah spesifikasi kebutuhan perangkat lunak.

b. Perancangan

Pada tahap perancangan kebutuhan atau spesifikasi perangkat lunak, yang dihasilkan pada tahap analisis transformasikan kedalam bentuk arsitektur perangkat lunak yang memiliki karakteristik mudah dimengerti dan tidak sulit untuk mengimplementasikannya. Hasil akhir dari tahap ini adalah perancangan flowchart pada aplikasi penjualan sembako di UD. Kerta Mandala Sumbawa Besar.

c. Implementasi

Pada tahap implementasi basis data merupakan upaya untuk membangun basis data fisik yang ditempatkan dalam media penyimpanan (disk).

d. Pengujian

Setelah perangkat lunak (komponen-komponen) selesai diimplementasikan makan pengujian dapat segera dimulai.

\section{HASIL DAN PEMBAHASAN}

\section{Perancangan Aplikasi}

Proses perancangan Membangun Aplikasi Pengelolaan Data Penjualan Sembako berbasis Dekstop untuk UD. Kerta Mandala Sumbawa Besar terdiri dari 5 (lima) bagian yaitu:

\section{Perancangan User Login} berikut:

Adapun perancangan dari User Login sebagai

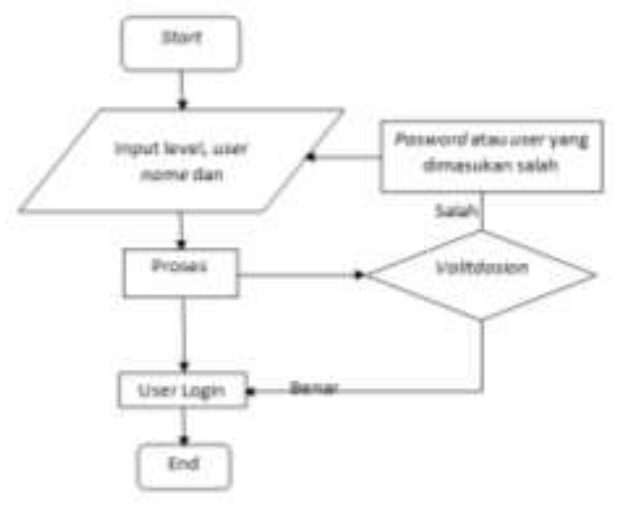

Gambar 1 Perancangan User Login 
Pada saat aplikasi dijalankan maka akan tampil Form Login, dimana user terlebih dahulu Login dengan memasukan level, user_name dan password yang telah terdaftar sebagai pengguna, agar dapat mengoperasikan aplikasi Penjualan. Namun apabila user_name dan password yang dimasukan salah, maka otomatis akan tampil pesan "password atau user yang dimasukan salah" dengan begitu user harus memasukan kembali data dengan benar. Jika data yang dimasukan benar maka aplikasi dapat dioperasikan oleh user.

\section{Perancangan Pengguna Aplikasi}

Adapun perancangan dari Pengguna Sistem sebagai berikut:

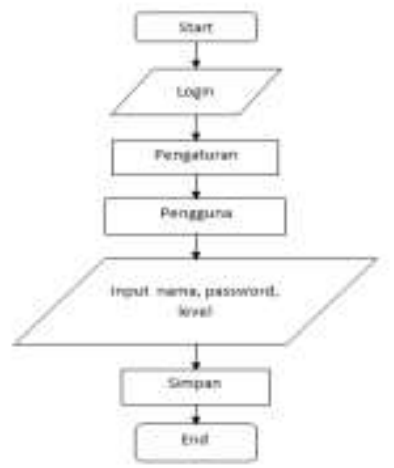

Gambar 2 Perancangan Pengguna Aplikasi

Delphi Apps akan terintegrasi dengan User apabila user telah terdaftar dengan jenis level yang dipilih. User yang belum melakukan pendaftaran akan di daftarkan terlebih dahulu oleh Owner, dengan login terlebih dahulu, kemudian pilih pengaturan dan masuk ke pengguna dan melakukan penginputan data dengan input nama, password dan level yang diinginkan, proses selesai. Penginputan data User yang baru hanya dapat dilakukan oleh Owner. Jika User telah terdaftar maka User dapat mengoperasikan Aplikasi tetapi data yang dapat dilihat dan gunakan adalah sesuai dengan level User.

\section{Perancangan Data Pelanggan}

Adapun perancangan dari Data Pelanggan sebagai berikut:

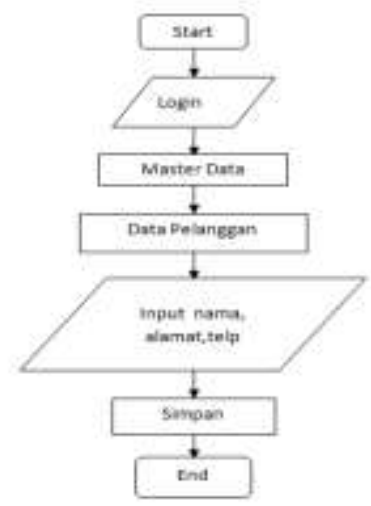

Gambar 3 Perancangan Data Pelanggan
Pada flowchart pelanggan hanya Owner yang dapat mendaftarkan pembeli tetap sebagai pelanggan. prosesnya pun dilakukan oleh owner dengan Login terlebih dahulu untuk, kemudian masuk ke Master Data untuk mengisi data pelanggan, dengan menginputkan data baru sebagai langganan. Setelah data sebagai pelanggan tersimpan, proses selesai. Dan data tersebut akan masuk secara otomatis ketika proses penjualan terjadi. Proses ini di lakukan agar pelanggan dapat melakukan pembelian dengan harga diskon\%. karena apabila pembeli tetap tidak di daftarkan terlebih dahulu maka pembeli tetap tidak bisa mendapatkan harga diskon\%. Dan harga diskon akan di input secara manual sesuai prosedur sebagai pelanggan baru.

\section{Perancangan Data produk}

Adapun perancangan dari Data Produk sebagai berikut:

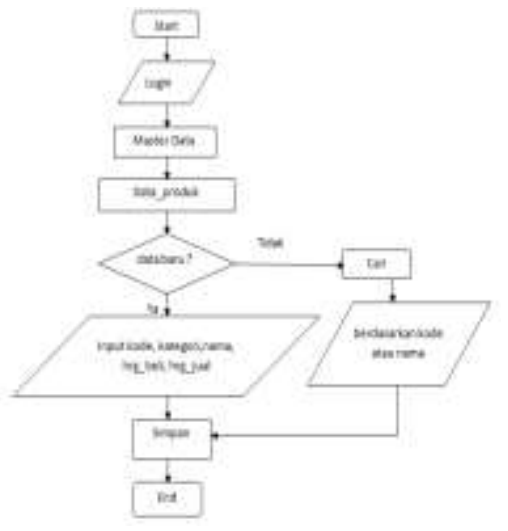

Gambar 4 Perancangan Data produk

flowchart produk merupakan langkah selanjutnya yang dilakukan sebelum melakukan pembelian produk, input datapun hanya bisa dilakukan oleh owner untuk menghindari kecurangan User lain dalam penginputan data, seperti harga beli. Prosesnya pun dilakukan dengan menjalankan program kemudian login user dan masuk ke data produk untuk melakukan pengisian data, namun jika ingin input data lama cukup cari data berdasarkan kode atau nama produk. dan jika data baru, maka harus input data dengan lengkap seperti kode produk, kategori produk, nama produk, harga beli dan harga jual. Simpan data, dan proses Selesai.

Perancangan Transaksi Penjualan

Adapun perancangan dari Transaksi Penjualan sebagai berikut: 


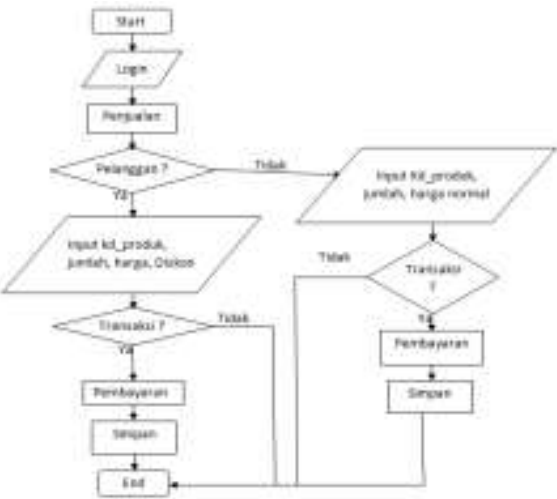

Gambar 5 Perancangan Transaksi Penjualan Pada flowchart Penjualan diatas pengoperasian Aplikasi dilakukan oleh Operator. Dimana jika pembeli adalah berstatus sebagai pelanggan maka prosesnya dilakukan dengan menginput terlebih dahulu nama pelanggan, kode produk, jumlah dan harga diskon\%. Setelah produk selesai diinputkan, maka operator menyebutkan jumlah dan harga semua produk dan bertanya, apakah pelanggan ingin melanjutkan transaksi? Jika iya, maka pelanggan melakukan pembayaran dan operator meyimpan data, proses selesai. Namun apabila tidak berstatus pelanggan maka penginputan produk dilakukan tanpa menginput nama pembeli tersebut, tetapi hanya menginput kode produk dan jumlah produk, setelah input produk selesai seperti biasa operator menyebutkan jumlah dan harga semua produk dan bertanya apakah pembeli ingin melanjutkan transaksi? Jika iya, maka pembeli..melakukan..pembayaran..Dan.proses.selesa i.

\section{Perancangan Database}

Perancangan database pada UD. Kerta Mandala Sumbawa Besar terdapat beberapa tabel yaitu tabel pengguna_sistem, tabel pelanggan, tabel produk, dan tabel penjualan. Tabel tersebut dapat digambarkan sebagai berikut:

\section{Perancangan Tabel Pengguna Sistem}

Adapun perancangan pada tabel Pengguna Sistem sebagai berikut:

\begin{tabular}{|l|l|l|l|}
\hline Nama file & $\begin{array}{l}\text { Tipe } \\
\text { Data }\end{array}$ & $\begin{array}{l}\text { Ukuran } \\
\text { File }\end{array}$ & Keterangan \\
\hline *Id_User & Integer & Long & Primary key \\
User_Name & Varchar & Integer & \\
Password & Varchar & 30 & \\
Level & Varchar & 15 & \\
& & 10 & \\
\hline
\end{tabular}

Tabel user login memiliki 4 file yaitu id_user, user_name, password dan level.

\section{Perancangan Tabel Pelanggan}

Adapun perancangan pada tabel pelanggan sebagai berikut:

\begin{tabular}{|l|l|l|l|}
\hline Nama File & $\begin{array}{l}\text { Tipe } \\
\text { Data }\end{array}$ & Ukuran & Keterangan \\
\hline Id_Pelanggan & Integer & Long & Primary \\
Nama & Varchar & Integer & key \\
Alamat & Varchar & 25 & \\
No_Tlp & Char & 30 & \\
& & 13 & \\
\hline
\end{tabular}

Tabel pelanggan memiliki 4 file yaitu id_pelanggan, nama, alamat dan nomer telepon.

\section{Perancangan Tabel Produk}

Adapun perancangan pada tabel produk sebagai berikut:

\begin{tabular}{|l|l|l|l|}
\hline Nama File & $\begin{array}{l}\text { Tipe } \\
\text { Data }\end{array}$ & Ukuran & Keterangan \\
\hline Kode & Char & 10 & Primary key \\
Id_Kategori & Varchar & 20 & Foreigen \\
Nama & Varchar & 30 & key \\
produk & Integer & Long & \\
Harga Beli & Integer & Integer & \\
Harga Jual & & Long & \\
& & Integer & \\
\hline
\end{tabular}

Tabel produk memiliki 5 file yaitu kode, id_kategori, nama produk, harga_beli dan harga jual

\section{Perancangan Tabel Penjualan}

Adapun perancangan pada tabel penjualan sebagai berikut:

\begin{tabular}{|l|l|l|l|}
\hline Nama File & Tipe Data & $\begin{array}{l}\text { Ukura } \\
\mathrm{n}\end{array}$ & $\begin{array}{l}\text { Keteranga } \\
\mathrm{n}\end{array}$ \\
\hline No_Faktur & Char & 30 & Primary \\
Id_Pelangga & Varchar & 30 & key \\
$\mathrm{n}$ & Varchar & 30 & Foreigen \\
Id_Produk & Integer & Long & key \\
Harga & Integer & Integer & Foreigen \\
Jumlah & Integer & Long & key \\
Total_belanj & Varchar & Integer & \\
a & Varchar & Long & \\
Bayar & Date/Tim & Integer & \\
Kembali & e & 30 & \\
Tanggal & & 30 & \\
& & & \\
\hline
\end{tabular}

Tabel penjualan memiliki 9 file yaitu no_faktur, id_pelanggan, id_produk, harga, jumlah, total_belanja, bayar, kembali dan tanggal.

\section{Implementasi menggunakan Delphi.7}

Pada tahapan ini dilakukan implementasi pada Sistem Penjualan Sembako UD. Kerta Mandala Sumbawa Besar, dimana diantaranya sebagai berikut:

\section{Implementasi tabel User Login}

Adapun proses implementasi pada tabel User login sebagai berikut: 


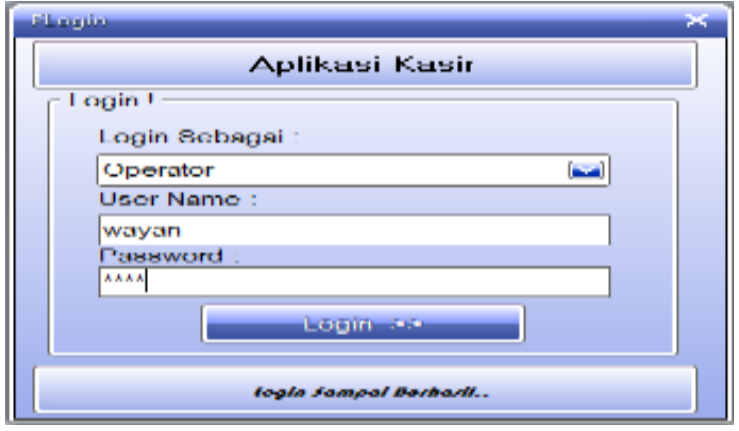

Gambar 5 Implementasi tabel User Login

Tabel User Login merupakan langkah awal yang dilakukan untuk dapat menggunakan aplikasi Penjualan, dengan memasukan data yang sudah terdaftar sebagai pengguna dengan jenis level yang dipilih dan user name serta password yang benar, maka user dapat menggunakan aplikasi penjualan.

\section{Implementasi Tabel Menu Utama}

Adapun proses implementasi pada tabel Menu Utama sebagai berikut:

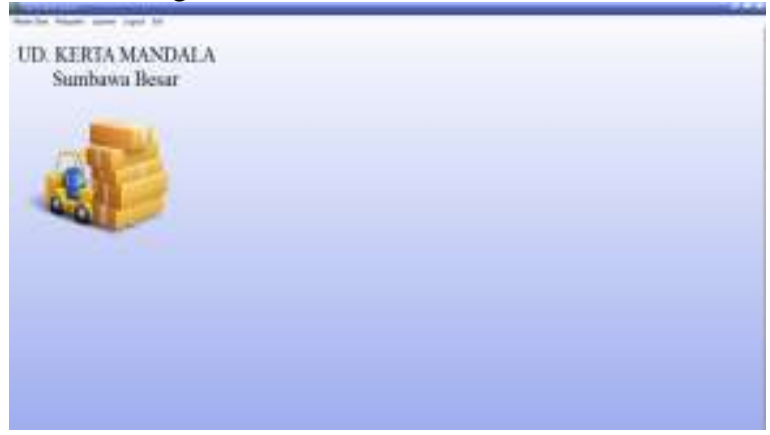

Gambar 6 Implementasi Tabel Menu Utama

Tabel Menu Utama adalah tabel selanjutnya yang tampil setelah melakukan Login dengan benar. Pada Menu Utama terdapat pilihan yang dapat dilakukan oleh User.

\section{Implementasi Tabel Produk}

Adapun proses implementasi pada tabel Produk sebagai berikut:

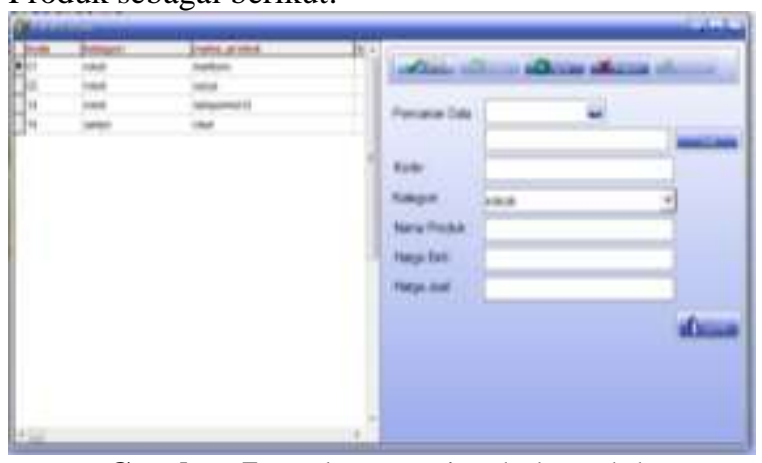

Gambar 7 Implementasi Tabel Produk

Pada tabel Produk adalah proses penginputan data yang dilakukan sebelum melakukan pembelian produk, seperti kode_produk, kategori, nama_produk harga_beli dan harga jual. tahap ini dilakukan untuk menyimpan data saat melakukan pembelian, karena data produk yang dipilih dan dibeli akan secara otomatis tampil saat Pembelian Produk.

\section{Implementasi Tabel Pelanggan}

Adapun proses Implementasi pada tabel Pelanggan sebagai berikut:

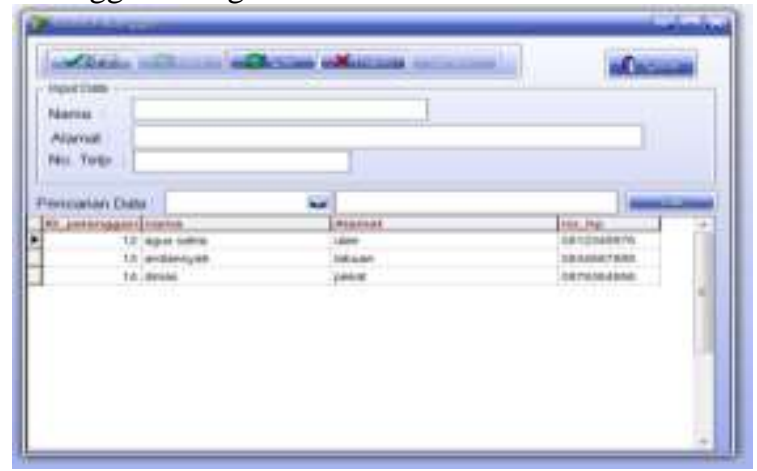

Gambar 8 Implementasi Tabel Pelanggan

Pada tabel pelanggan adalah proses pendaftaran Pelanggan dilakukan, dimana proses pendaftaran hanya dapat di lakukan oleh Owner. Dengan menginput nama, alamat dan nomer telepon sebagai syarat untuk menjadi Pelanggan. Langkah ini bertujuan agar saat proses Transaksi, Pelanggan bisa mendapatkan potongan harga (diskon\%).

\section{Implementasi Tabel Transaksi Penjualan dengan pelanggan}

Adapun proses implementasi pada tabel Transaksi Penjualan dengan Pelanggan sebagai berikut:

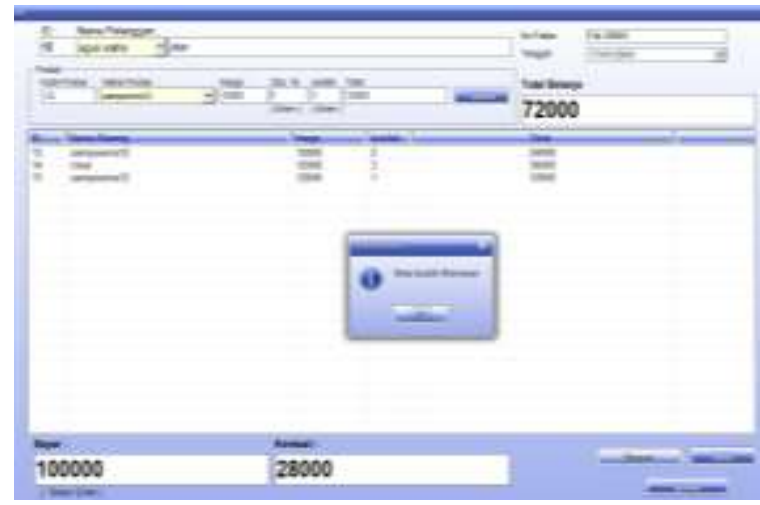

Gambar 9 Implementasi Tabel Transaksi Penjualan dengan pelanggan

Tabel Transaksi Penjualan dengan Pelanggan adalah proses Transaksi yang hanya dapat dilakukan dengan pembeli yang sudah terdaftar sebagai Pelanggan. Karena Pembeli yang sudah terdaftar sebagai Pelanggan akan mendapatkan potongan harga (diskon\%). Proses awal dilakukan dengan memilih nama Pelanggan, maka secara otomatis kolom diskon akan tampil, kemudian memasukan jumlah diskon secara manual setelah pemilihan nama produk dilakukan. Selanjutnya mamasukan jumlah produk lalu tekan enter maka total harga akan tampil, lalu dilakuakan pertanyaan "apakah Transaksi ingin dilanjutkan?", jika iya maka lakukan validate untuk mengunci Pembelian, kemudian masukan jumlah bayar lalu enter maka jumlah kembali secara otomatis akan tampil dan selanjutnya dilakukan penyimpanan data Transaksi Penjualan. 


\section{Implementasi Tabel Transaksi Penjualan dengan Non Pelanggan}

Adapun proses implementasi pada tabel Transaksi Penjualan dengan Non Pelanggan sebagai berikut:

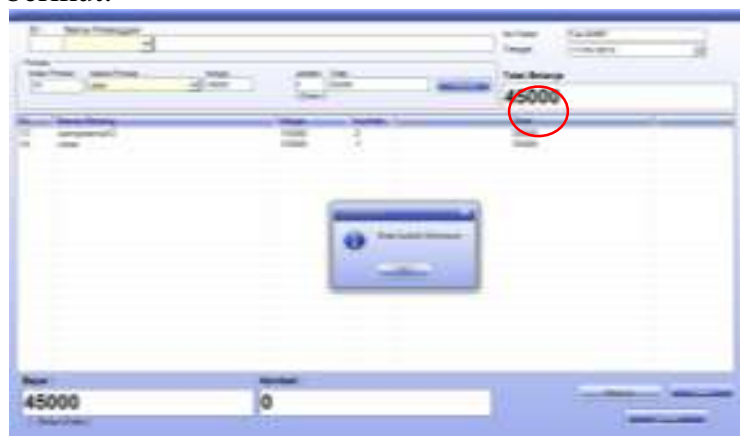

Gambar 10 Implementasi Tabel Transaksi Penjualan dengan non Pelanggan

Tabel Transaksi Penjualan dengan Non Pelanggan adalah proses Transaksi yang dilakukan dengan Pembeli yang belum terdaftar sebagai Pelanggan. Dimana Pembeli tidak mendapatkan potongan harga (diskon\%) seperti Pelanggan. Proses awal dilakukan tanpa memilih nama Pelanggan, maka secara otomatis kolom diskon tidak akan tampil, selanjutnya lakukan pemilihan nama produk, maka secara otomatis harga satuan akan tampil, lalu masukan jumlah produk dan tekan enter maka total harga akan tampil, lalu dilakuakan pertanyaan “apakah Transaksi ingin dilanjutkan?”, jika iya maka lakukan validate untuk mengunci Pembelian, kemudian masukan jumlah bayar, lalu enter maka jumlah kembali secara otomatis akan tampil dan selanjutnya dilakukan penyimpanan data Transaksi Penjualan.

\section{Implementasi Tabel Pengguna}

Adapun proses Implementasi pada tabel pengguna sebagai berikut:

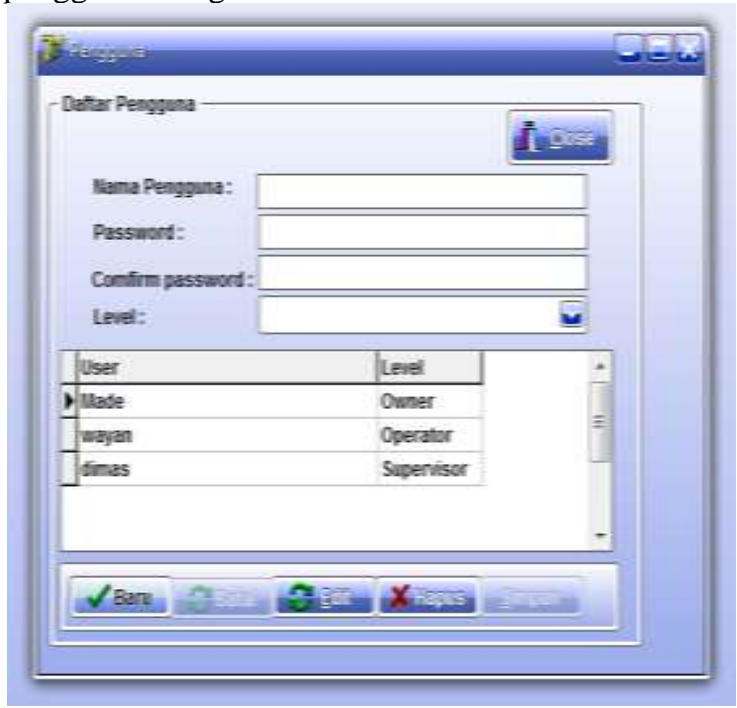

Gambar 11 Implementasi Tabel Pengguna

Pada tabel Pengguna pengoperasian dilakukan oleh Owner, dimana prosesnya dilakukan dengan memasukan data baru seperti Nama
Pengguna, Password, dan Level Pengguna. Tahap ini dilakukan agar pengguna yang satu dengan yang lain tidak mengganggu tugas masing-masing, kecuali Owner.

\section{Implementasi Tabel Laporan Penjualan berdasarkan nama Pelanggan}

Adapun proses Implementasi pada Laporan Penjualan berdasarkan nama Pelanggan sebagai berikut:
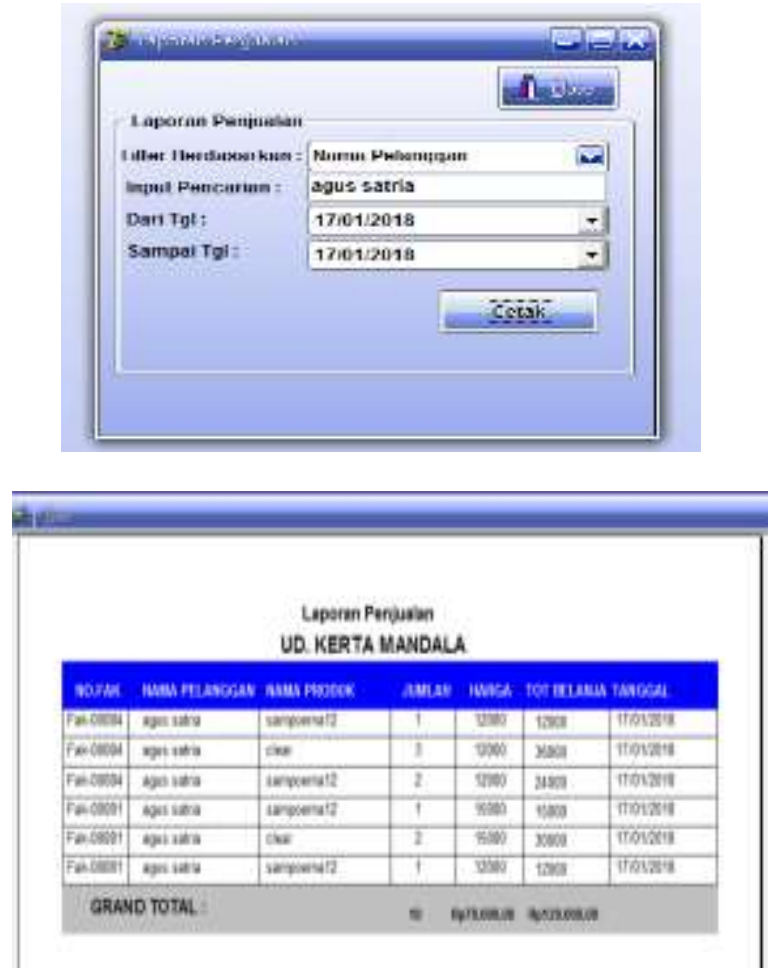

Gambar 12 Implementasi Tabel Laporan Penjualan berdasarkan nama Pelanggan

Pada tahap ini dilakukan pelaporan hasil dari penjualan yang berdasarkan Pelanggan. Proses dilakukan dengan menginput nama pelanggan dan tanggal penjualan. Langkah ini dilakukan agar memudahkan dalam melihat data pelanggan yang melakukan transaksi pembelian.

\section{Implementasi Tabel Laporan Penjualan berdasarkan nama produk}

Adapun proses implementasi Laporan Penjualan berdasarkan nama Produk sebagai berikut: 

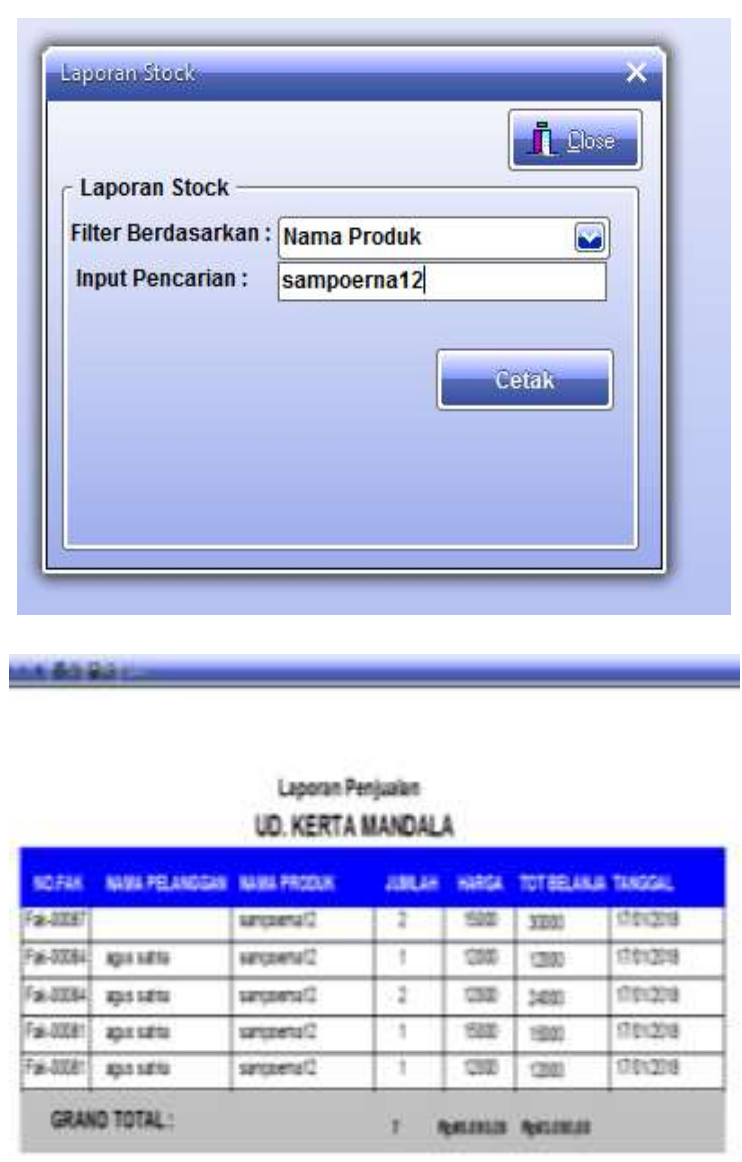

Gambar 13 Implementasi Tabel Laporan Penjualan berdasarkan nama produk

Pada tahap ini adalah melakukan pelaporan penjualan berdasarkan nama Produk, proses ini dilakukan dengan memilih kategori dan menginput nama produk. Langkah ini dilakukan agar dapat mudah melihat data sesuai dengan jenis produk yang.terjual.

Untuk memperjelas penyajian, hasil penelitian disajikan secara cermat agar mudah dipahami, misalnya dapat ditunjukkan dalam bentuk tabel, kurva, grafik, gambar, foto, atau bentuk lainnya sesuai keperluan secara lengkap dan jelas. Perlu diusahakan agar saat membaca hasil penelitian dalam format tersebut, pembaca tidak perlu mencari informasi terkait dari uraian dalam pembahasan. Akhir dari bagian ini memuat keterangan tentang kelebihan dan kelemahan sistem, yang dideskripsikan secara terinci.

\section{KESIMPULAN DAN SARAN}

Dari hasil analisis dan perancangan aplikasi yang telah dilakukan sebelumnya, maka penulis dapat mengambil kesimpulan bahwa Rancang Bangun
Aplikasi Pengelolaan Data Penjualan Sembako Berbasis Dekstop Untuk UD. Kerta Mandala telah selesai dibangun menggunakan bahasa pemrograman Delphi 7, Database Microsoft Access. Aplikasi ini memilki beberapa fitur berupa data pelanggan, data produk yang dijual, serta data transaksi penjualan dan pembelian.

Saran untuk mengembangkan Aplikasi Pengelolaan Data Penjualan Sembako di UD. Kerta Mandala Sumbawa Besar, harus menggunakan hardware tambahan seperti Scan Barcode agar lebih memudahkan dan menghemat waktu saat transaksi penjualan.

\section{DAFTAR PUSTAKA}

[1] Widajanti, E. "Peran Teknologi Informasi Untuk Mencapai Keunggulan Kompet itf'. Jurnal Akuntansi dan Sistem Informasi, Vol.6, No. 1, hal: 60-71. 2008.

[2] Hidayatullah, M., Hendrawan, F., Andriani, T., \& Esabella, S. (2019, November). DesktopBased Population Data Information System to Support The Sumbawa Electronic Government in Rhee District. In IOP Conference Series: Earth and Environmental Science (Vol. 396, No. 1, p. 012032). IOP Publishing.

[3] Pressman, R. S,. 2002. "Rekayasa Perangkat Lunak: Pendekatan Praktisi Buku I”. Andi: Yogyakarta.

[4] Junaidi, J., Arifin, R., \& Septiani, A. (2015). Rancang Bangun Aplikasi Sistem Inventory Berbasis Desktop Menggunakan JSE. Proceedings Konferensi Nasional Sistem dan Informatika (KNS\&I).

[5] Nugraha, W., Syarif, M., \& Dharmawan, W. S. (2018). Penerapan Metode SDLC Waterfall dalam Sistem Informasi Inventori Barang Berbasis Desktop. JUSIM (Jurnal Sistem Informasi Musirawas), 3(01), 23-29.

[6] Ansari, N. Y., \& Haq, M. (2020). "Rancang Bangun Aplikasi Pengelolaan Pemesanan Tiket Pada Po. Panca Sari Tour Dan Travel Sumbawa Berbasis Web". Hexagon Jurnal Teknik dan Sains, 1(1), 10-22.

[7] Faizah, F. I., \& Sophia, E. (2016). Aplikasi Persediaan Barang Pada Toko Rajawali Malang Berbasis Desktop. Dinamika Dotcom: Jurnal Pengembangan Manajemen Informatika dan Komputer. 